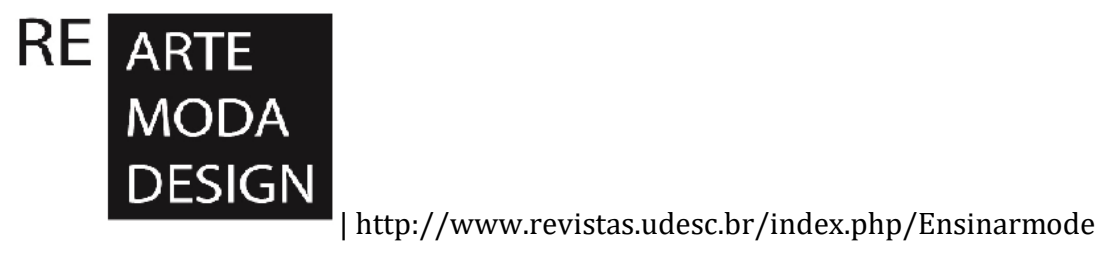

\title{
VALORAÇÃO DOS CURSOS DE MODA SEGUNDO O NOME E GRAU ACADÊMICO
}

\author{
Valuation of undergraduate programs in Fashion in Brazil according to their \\ names and academic degrees
}

Adriana Tulio Baggio ${ }^{1}$

\section{RESUMO}

Este trabalho apresenta uma análise quantitativa da presença de cursos superiores em moda no Brasil segundo o nome e o grau acadêmico. Considerando que a maior parte dos cursos chamados Design de Moda é ofertada em grau tecnológico, que a maior parte dos cursos chamados Moda é oferta em grau bacharelado, e que esta divisão manifesta certas valorações sobre o ensino de moda, como se dá essa relação nas regiões brasileiras e nas instituições públicas e privadas? Secundariamente, qual a possível explicação para predominância de cursos tecnológicos na moda, o que destoa da média nacional? Estas questões são investigadas a partir da observação de dados numéricos disponibilizados pelo Ministério da Educação em diferentes fontes, e pela consulta a edições do Catálogo Nacional de Cursos de Tecnologia. Os resultados mostram que os cursos de Design de Moda tecnológicos são maioria tanto em instituições privadas quanto públicas. Nestas últimas, porém, eles são ofertados nos Institutos Federais e nas Universidades Tecnológicas. Universidades federais e estaduais ofertam mais cursos de bacharelado em Moda. Nota-se, portanto, uma homologação de elementos valorados positivamente: Moda, bacharelado, universidade pública. Quando à predominância dos tecnológicos, além das questões de regulamentação e incentivo governamental, uma outra causa possível seria um efeito de sentido de maior acessibilidade para a formação nesta área proporcionada por esse grau acadêmico, em relação ao bacharelado.

Palavras-chaves: Formação em moda. Análise quantitativa. Axiologia de valor.

\footnotetext{
${ }^{1}$ Bacharel em Comunicação Social (UFPR), Mestre em Letras (UFPB) e doutora em Comunicação e Semiótica (PUC-SP). Estágio pós-doutoral em andamento na UTFPR, no PPG Tecnologia e Sociedade. Pesquisadora do Centro de Pesquisas Sociossemióticas da PUC-SP.

E-mail: atbaggio@gmail.com | Lattes: http://lattes.cnpq.br/0891805528342991 


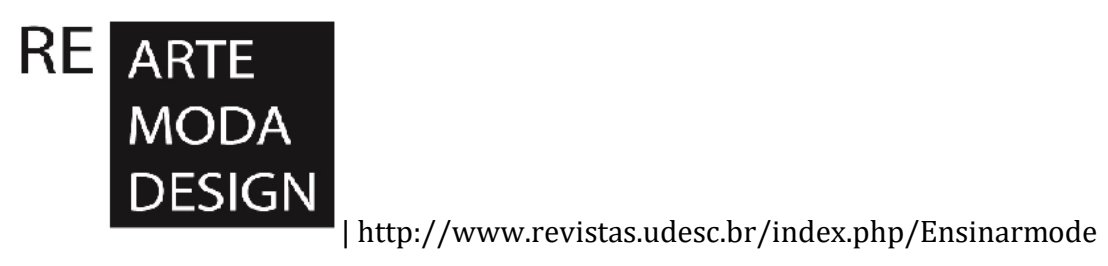

\begin{abstract}
$^{2}$
This study presents a quantitative analysis of the presence of undergraduate programs in Fashion in Brazil. Given that most programs known as Fashion Design are offered as a professional-technical degree, that most programs known as Fashion are offered as a bachelor's degree, and that this division manifests certain valuations about the teaching of this subject, the following questions were posed: 1) How does this relationship work in Brazilian regions and in public and private institutions? 2) What reason could explain the predominance of professionaltechnical programs in Fashion, considering that most programs in Brazil are offered as a bachelor's degree? These questions were investigated by observing numerical data provided by the Ministry of Education, and by consulting issues of the National List of Technological Courses. The results demonstrate that there is a majority of professional Fashion Design programs at both private and public institutions. In the latter case, however, they are offered at Federal Institutes of Education, Science and Technology and Technological Universities. Federal and state universities, in their turn, offer more bachelor's degrees in Fashion. A ratification of elements that are positively valued is thus observed: Fashion, bachelor's degree, public university. As for professional programs, a possible cause for their predominance - in addition to regulatory issues and government incentive - could be their higher acceptance rates, in comparison to those of bachelor's degrees.
\end{abstract}

Keywords: Fashion Education. Quantitative analysis. Axiology.

${ }^{2} \mathrm{O}$ resumo deste artigo foi vertido para o inglês pela equipe do CAPA - Centro de Assessoria de Publicação Acadêmica da UFPR (www.capa.ufpr.br). 


\section{RE ARTE \\ MODA \\ DESIGN \\ | http://www.revistas.udesc.br/index.php/Ensinarmode}

\section{INTRODUÇÃO}

Quem se dedica ao fazer investigativo percebe que não existe um ponto zero da pesquisa, um estado anterior de absoluta ignorância que sofrerá uma mudança, transformando-se em conhecimento. É somente a familiaridade com determinado tema que proporcionará o surgimento de questões que poderão ser respondidas com a pesquisa científica.

Este momento, o surgimento da questão, pode dar-se de várias formas. Duas das mais comuns são: 1) o sujeito dedica-se ativa e conscientemente ao assunto de interesse, para descobrir nele um aspecto ainda não (ou pouco) explorado. Este aspecto embasará a formulação da questão de pesquisa; 2) o sujeito dedica-se a um assunto de interesse com base em certas intenções, mas um aspecto intrigante, não relacionado a estas intenções iniciais, emerge do objeto e passa a constituir a questão de pesquisa.

O surgimento da questão que orienta este artigo ocorreu da segunda forma, e teve a ver com a observação de dados sobre a educação superior brasileira disponibilizados pelo Ministério da Educação no sistema e-MEC - Cadastro de Instituições e Cursos de Educação Superior e no Censo da Educação Superior do Inep - Instituto Nacional de Estudos e Pesquisas Educacionais. Estas bases governamentais podem ser úteis tanto para auxiliar a resolução de questões de pesquisa previamente definidas, quanto para a apreensão de relações que acabam se destacando a partir da observação e manipulação destes dados.

Ao se fazer uma contagem, por meio da plataforma e-MEC, dos cursos superiores em moda oferecidos no Brasil, duas relações chamam a atenção: dentre os possíveis nomes de curso, o predominante é Design de Moda, que ocorre em quantidade muitíssimo maior do que apenas Moda. Há uma explicação clara para isso, que é a determinação do Ministério da Educação, em 2004, de integrar a Moda à área de Design e de incluir esta área no nome dos cursos.

Por sua vez, cursos com este nome são oferecidos majoritariamente no grau tecnológico, que se diferencia dos bacharelados ou licenciaturas, entre outros aspectos, pela menor quantidade de carga horária e, portanto, de duração (2 ou 2,5 


\section{RE ARTE \\ MODA \\ DESIGN \\ | http://www.revistas.udesc.br/index.php/Ensinarmode}

anos para os tecnológicos, 4 anos para os demais). Já os cursos que permanecem sendo chamados Moda são oferecidos principalmente no grau bacharelado.

Diante disso, vem a seguinte questão: como se dá essa relação quando se considera alguns recortes, como o de estados e regiões do país e a categoria administrativa das instituições de ensino - pública ou privada?

Tanto o nome dos cursos quanto os graus em que são oferecidos têm sido bastante discutidos em investigações sobre a formação acadêmica em moda no país, a exemplo dos trabalhos de Grazyella Cristina Oliveira de Aguiar (2015) e Cyntia Tavares Marques de Queiroz (2014). Estes trabalhos mostram que os nomes e as modalidades estão relacionados à legislação e a distintas propostas e organizações curriculares. Mas além disso, também manifestam diferentes atribuições de valor aos cursos, às instituições, aos profissionais egressos. Esta valoração estende-se aos locais onde são ofertados e é impactada igualmente pela categoria administrativa das instituições - pública ou privada.

A situação observada na moda destoa da média encontrada no país, que é relativa a todas as áreas. $\mathrm{Na}$ moda, como visto, a maior parte dos cursos é ofertada em grau tecnológico. Já no contexto nacional, segundo o Resumo Técnico do Censo da Educação Superior de 2014, os tecnológicos são minoria: correspondem a 19,5\% dos cursos, enquanto os bacharelados são $56,6 \%$ e as licenciaturas, 23,9\%. (INSTITUTO..., 2016, p. 13). Tal constatação destina uma outra questão a ser tratada no artigo: quais as possíveis explicações para esta discrepância?

Os objetivos deste trabalho, portanto, estão primordialmente relacionados a estas duas questões. Primeiro, pretende-se verificar, em termos quantitativos, como se dá a relação entre o estado ou a região do país, ou o tipo de instituição, e as modalidades de cursos oferecidos (seja no aspecto do nome, seja no do grau acadêmico). Segundo, buscar em outras bases de dados as possíveis explicações para que a predominância dos cursos tecnológicos na moda seja muito maior do que a média nacional. Por fim, deseja-se ainda contrapor tais relações quantitativas a informações presentes em documentos oficiais sobre o ensino superior em moda, como o Catálogo Nacional de Cursos Superiores de Tecnologia. 


\title{
RE ARTE \\ MODA \\ DESIGN
}

| http://www.revistas.udesc.br/index.php/Ensinarmode

A escolha dos dados analisados nesta pesquisa orienta-se, de certa forma, pelos procedimentos metodológicos operados na semiótica discursiva ${ }^{3}$ : delimitação do corpus pelo sujeito-pesquisador, constituindo-o em um texto, um todo de sentido; descrição dos elementos integrantes deste texto e observação de suas articulações internas; interpretação das relações constituídas; observação das atribuições de valor.

Entende-se, portanto, que estes dados secundários, sejam numéricos ou verbais, constituem um todo de significação que produz efeitos de sentido sobre o ensino superior em moda no Brasil. Os resultados aqui encontrados podem ser confrontados àqueles obtidos por abordagens de outra natureza, para verificar em que medida o texto articula-se ao contexto.

\section{ANÁLISE QUANTITATIVA DAS ESCOLAS SUPERIORES EM MODA NO BRASIL: CRITÉRIOS ADOTADOS E RELAÇÕES ENCONTRADAS.}

O levantamento que deu origem às questões deste trabalho foi feito em dezembro de $2016^{4}$, por meio - como já informado - do sistema e-MEC, que é

\begin{abstract}
[...] base de dados oficial e única de informações relativas às Instituições de Educação Superior - IES e cursos de graduação do Sistema Federal de Ensino. Os dados do Cadastro e-MEC devem guardar conformidade com os atos autorizativos das instituições e cursos de educação superior, editados com base nos processos regulatórios competentes (e-MEC, 2017).
\end{abstract}

Esta descrição seria de pouca relevância para o potencial público leitor deste artigo, já familiarizado com a plataforma, não fosse a inconsistência dos dados apresentados. Ou seja, os dados oficiais não correspondem necessariamente à realidade, o que exige um trabalho de higienização dos resultados encontrados.

\footnotetext{
3 "Nada impede que 'um pequeno número de fatos' que permite a construção do modelo seja nem mais nem menos que um corpus representativo limitado, constituído de maneira mais ou menos intuitiva, nem que os critérios de gramaticalidade e de aceitabilidade - que controlam a projeção das regras - não pareçam mais seguros que as da exaustividade e da adequação que se supõe substituam" (GREIMAS; COURTÉS, 2008, p. 105).

${ }^{4}$ Considerando o tempo decorrido entre o levantamento e a publicação deste artigo, e também as características de busca e apresentação dos dados da plataforma e-MEC, não é impossível que haja desatualização ou incorreção de dados. Neste trabalho, a análise dos dados numéricos busca mostrar articulações mais gerais; neste sentido, eventuais inconsistências não prejudicam as relações observadas no contexto mais amplo. 


\section{RE ARTE \\ MODA \\ DESIGN}

Diante disso, antes de apresentar os resultados, parece-nos importante descrever o passo-a-passo do levantamento.

A pesquisa no sistema utilizou a ferramenta "Consulta Avançada". A "Busca por Curso de Graduação" foi feita com o termo "moda". Nenhum filtro foi marcado, já que o objetivo era obter todos os cursos, de todo o país, das modalidades presencial e a distância e nos graus bacharelado, licenciatura, tecnológico e sequencial. Os dados resultantes desta busca foram conferidos individualmente, mostrando entradas repetidas e cursos extintos, que foram desconsiderados.

Em um segundo momento, todos os cursos foram verificados por meio de busca na internet. Se o curso efetivamente aparecia no site instituição de ensino como "em funcionamento", era contabilizado. Cursos indicados no e-MEC mas não mencionados nos sites das respectivas IES foram desconsiderados. Cursos ofertados na mesma cidade, mas em campi e com coordenações diferentes, foram considerados separadamente, e não como o mesmo curso.

No sistema e-MEC, os cursos a distância de abrangência nacional aparecem em todas as unidades da federação que tenham polos deste curso. Sendo assim, um mesmo curso EAD foi contabilizado como 27 cursos, ou seja: um curso para cada um dos 26 estados e mais um para o Distrito Federal.

Com base em todos estes critérios, o levantamento apontou a existência de 180 cursos. Destes, a grande maioria - 85\% - chama-se "Design de Moda". Se considerarmos denominações que incluem o termo "design" no nome - "Design de Moda - Estilismo"; "Design de Moda - Modelagem"; "Design de Moda e Vestuário"; "Moda e Design"; "Moda, Design e Estilismo" -, a participação sobe para 88\%. O segundo nome mais frequente é "Moda", com pouco mais de 10\% de ocorrência. Os outros nomes de cursos encontrados foram "Negócios da Moda"; "Têxtil e Moda"; "Produção Têxtil".

Levando em conta o grau acadêmico dos cursos, $70 \%$ são tecnológicos e $30 \%$ são bacharelados (não foram encontrados licenciaturas ou sequenciais). E quando cruzamos as variáveis nome do curso e grau acadêmico, surge o perfil que nos instigou a esta pesquisa: mais de $81 \%$ (123) dos cursos chamados "Design de Moda" são tecnológicos. Já dentre os 19 que se chamam "Moda", 18 são bacharelados. 


\section{RE ARTE \\ MODA \\ DESIGN}

http://www.revistas.udesc.br/index.php/Ensinarmode

\subsection{Nomes de curso, graus acadêmicos e suas valorações nos discursos sobre a formação em moda.}

A escolha destas categorias para a análise quantitativa que faremos em seguida se justifica, como já sinalizado, pelas distintas valorações ${ }^{5}$ que seus elementos adquirem nos discursos sobre a formação superior em moda. Queiroz (2014) aborda em sua pesquisa tanto a conotação negativa que teriam os cursos tecnológicos - opinião manifestada por depoimentos de docentes - quanto a resistência de certos segmentos à integração da moda ao design. Esta resistência foi observada em 1998, em documento enviado ao Ministério da Educação e assinado por profissionais e instituições que defendiam a autonomia da moda como campo; em 2004, na efetiva implantação das diretrizes do MEC que "enquadravam" a moda ao design; e permanecia ainda em 2012, ocasião em que a pesquisadora realizou as entrevistas para sua tese (QUEIROZ, 2014, p. 17-19, 94).

De fato, Queiroz observa que, apesar das diretrizes de 2004, alguns cursos continuam sendo chamados de "Moda" (QUEIROZ, 2014, p. 100-101). levantamento também atesta essa ocorrência e, na medida em que o e-MEC é uma base de dados oficial, ela parece ser aceita ou tolerada pelo Ministério da Educação.

Por outro lado, as instituições que assumem o enquadramento ao Design beneficiam-se não só da aprovação governamental, mas também de diretrizes curriculares e avaliações oficiais bastante claras, o que facilita a implantação e a manutenção dos cursos, especialmente no grau tecnológico. Esta situação é observada por Queiroz (2014) e também por Aguiar (2015). E é numa questão posta por Aguiar que se completa a justificativa para a observação dos cruzamentos entre nome de curso, grau acadêmico e categoria administrativa das instituições: "Como os cursos superiores de moda são vistos hoje no Brasil, em meio a tantas

\footnotetext{
${ }^{5}$ O conceito de valor aqui adotado é o semiótico (GREIMAS; COURTÉS, 2008, p. 526-528), ou seja, os elementos de uma categoria, postos em relação, são considerados eufóricos (positivos) ou disfóricos (negativos) apenas quando assumidos pelo sujeito de uma narrativa. Desta forma, os elementos em si não têm valor intrínseco positivo ou negativo. Estas atribuições são atualizadas quando os elementos são colocados em discurso. As relações que se observa neste trabalho são, na categoria grau acadêmico, entre bacharelado x tecnológico; na categoria nome, entre Moda x Design de Moda; na categoria administrativa das instituições, entre pública x privada. Os discursos mais gerais sobre a educação superior no Brasil, e aqueles específicos sobre a educação em moda, atribuem certos valores a cada elemento destas categorias, e são a estas valorações que nos referimos.
} 


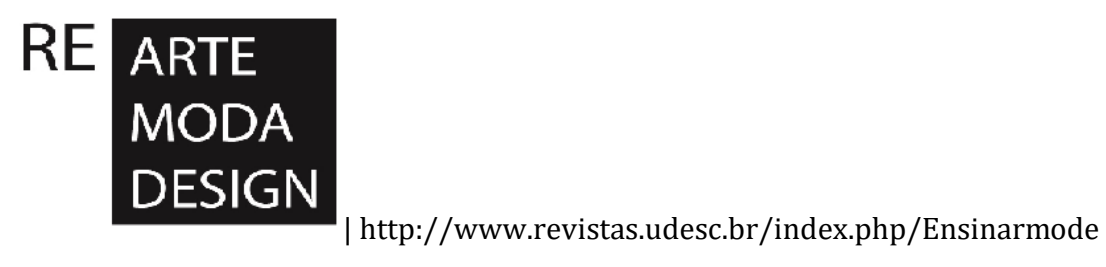

mudanças, sem ter legitimidade de fato e diretrizes específicas para a área?" (AGUIAR, 2015, p. 12, grifos nossos).

A constatação de uma falta de legitimidade da moda enquanto área do saber e de uma ausência de diretrizes específicas parece manifestar um embate que se observa também nos números: de um lado, a busca de legitimação da área pela manutenção do nome Moda, em um grau axiologizado positivamente em certos discursos da educação superior brasileira, que é o bacharelado; de outro, a busca pela chancela governamental, o que implica a adoção do nome Design de Moda, e pela conveniência da oferta em grau tecnológico.

No primeiro caso, talvez se perca em praticidade (dificuldade nas avaliações oficiais, falta de enquadramento a uma área específica etc.) o que se ganha em legitimidade (como área autêntica e autônoma). No segundo, o contrário: ganha-se em praticidade pela maior facilidade na organização curricular do curso (pois as diretrizes estão claramente apresentadas nos Catálogos de Cursos, como veremos adiante), pelo posicionamento mais facilmente assimilável pelo mercado e pelo melhor desempenho dos alunos nas avaliações oficiais. No entanto, cursos de menor duração, discursivizados mais pelo fazer e alocados em uma área nãooriginal, não teriam a mesma autenticidade.

Neste momento, vale reforçar que "legitimidade" e "praticidade" são valores não intrinsecamente positivos ou negativos. Estas classificações estão presentes nos discursos sobre a formação em moda e tanto um quanto outro valor podem ser almejados pelos sujeitos de distintas narrativas - as instituições, os docentes, os alunos, o mercado de trabalho que acolherá os egressos destes cursos -, como de fato acontece.

Feita esta discussão sobre as valorações dos nomes dos cursos e dos graus acadêmicos, passamos à análise quantitativa da presença destes cursos por tipo de instituição e nos estados e regiões brasileiras. 


\section{RE ARTE \\ MODA \\ DESIGN \\ | http://www.revistas.udesc.br/index.php/Ensinarmode}

\subsection{A relação entre as modalidades dos cursos, os estados/regiões em que são ofertados e o tipo de instituição.}

Para observar a distribuição dos cursos por locais e pela categoria administrativa das instituições, colocamos em suspensão uma das modalidades do levantamento preliminar, que é o ensino a distância. O levantamento encontrou duas instituições que oferecem estes cursos, ambos tecnológicos e chamados Design de Moda. Uma delas atua em todo país e, portanto, como já vimos, contribuiu com 27 cursos para a contagem geral. A outra atua apenas no estado de Santa Catarina. Desta forma, excluindo estas entradas, o corpus anterior de 180 cursos passa a ser composto de 152 cursos, apenas presenciais (um deles, semipresencial, foi incluído neste conjunto).

O levantamento classificou os cursos de moda por estado e cidade em que são oferecidos, pela categoria administrativa da instituição (se é privada ou pública), pelo nome do curso e pelo grau acadêmico. Uma planilha contendo estas categorias permite inúmeros tipos de cruzamento. No caso deste trabalho, os cruzamentos realizados destinam-se a observar a distribuição de cursos chamados "Design de Moda" e "Moda", nos graus tecnológico e bacharelado, nos estados e regiões do país e nas instituições públicas e privadas.

A maior parte dos cursos (126 - 80\%) é oferecida em instituições privadas. Nestas instituições, $52 \%$ dos cursos são em grau tecnológico e, portanto, $48 \%$ em grau bacharelado. Cursos em grau tecnológico também são maioria nas 26 instituições públicas encontradas no levantamento: são 15 cursos, somando $60 \%$ do total.

Estes cursos em instituições públicas são oferecidos majoritariamente em Institutos Federais de Educação, Ciência e Tecnologia; um deles está em uma Universidade Tecnológica Federal. Não há cursos tecnológicos em Universidades Federais. Nestas estão os cursos de bacharelado, que também aparecem em universidades estaduais (na mesma quantidade que as federais) e em uma instituição municipal.

Quanto ao nome, no geral mais de $83 \%$ dos cursos são de Design de Moda. Mas entre os tecnológicos, cursos chamados Design de Moda representam 97\%; 


\section{RE ARTE \\ MODA \\ DESIGN}

| http://www.revistas.udesc.br/index.php/Ensinarmode

entre os bacharelados, $32 \%$. Ou seja, nos bacharelados, $68 \%$ dos cursos têm nomes diferentes de "Design de Moda".

Dos cursos chamados apenas "Moda" ou que possuem "Moda" como termo principal, 21 são de bacharelado e apenas 1 é tecnológico. Cursos com este tipo de nome são 37\% nas instituições públicas e 18\% nas instituições privadas.

Até aqui observa-se, portanto, que os cursos em grau tecnológico são maioria tanto em instituições privadas quanto públicas. Nestas últimas são até em maior proporção do que nas primeiras. No entanto, são ofertados especialmente em instituições que focam na formação técnica profissional. Cursos de bacharelado em instituições públicas vão aparecer nas universidades federais e estaduais mais voltadas à formação acadêmico-científica.

Quanto ao nome, Design de Moda e suas variações estão na maior parte dos cursos tecnológicos, e Moda e suas variações têm participação preponderante nos bacharelados. Cursos com este nome também são maioria nas instituições públicas, especialmente as universidades federais.

Se for aceitável que existe uma axiologia de legitimidade, como vimos antes, que coloca a Moda e o bacharelado em posição eufórica, e o Design de Moda e o tecnológico em posição disfórica, nota-se que os polos positivos de cada eixo são encontrados principalmente em instituições públicas de ensino, especialmente as universidades federais e estaduais. Tais instituições, por sua vez, devido a uma combinação de aspectos concretos e simbólicos, são discursivamente consideradas como centros privilegiados tanto de formação discente como de atuação docente.

Se alguns discursos da formação em moda buscam a autonomia da área como campo do saber e entendem o grau bacharelado como a proposta mais adequada e consistente, ou seja, se a combinação autonomia e formação teórica for um binômio que manifesta a excelência no ensino e na pesquisa em moda, é nas universidades federais que estariam os centros de excelência. Mas como tais centros se distribuem entre os estados e as regiões brasileiras?

Antes de tudo, é importante lembrar que, ao retirar os cursos a distância, muitos estados não aparecem no levantamento por não abrigarem instituições que ofertam cursos presenciais de moda. São eles: Acre, Rondônia, Roraima, Amapá e Tocantins, na região Norte, e Maranhão e Alagoas, na região Nordeste. 


\section{RE ARTE \\ MODA \\ DESIGN}

| http://www.revistas.udesc.br/index.php/Ensinarmode

$\mathrm{Na}$ região Norte, há 2 cursos, 1 tecnológico em Design de Moda e 1 bacharelado em Moda, ambos em instituições privadas. Os 9 cursos da região Centro-Oeste são de Design de Moda, sendo 2 deles de bacharelado. Ambos são ofertados em Goiânia, um em uma instituição privada, outro em uma universidade federal. Na região Nordeste, há 22 tecnológicos chamados Design de Moda e 3 bacharelados, 2 com este mesmo nome (um em instituição privada e outro em universidade federal) e um que entraria na categoria "Moda" e suas variações (em universidade federal).

A região Sudeste abriga 63 cursos, sendo 37 tecnológicos e 26 bacharelados (30\%). Onze destes bacharelados têm o nome "Moda" e suas variações; 2 deles são oferecidos em universidades federais, ambas de Minas Gerais. Por fim, na região Sul encontra-se 53 cursos, sendo 32 tecnológicos e 22 bacharelados (32\%). Todos os tecnológicos se chamam Design de Moda, e cinco deles são ofertados em instituições públicas - Institutos Federais e Universidade Tecnológica. Dos bacharelados, 14 se chamam "Design de Moda" e suas variações e 8 se chamam "Moda". Destes 8, 3 são ofertados por universidades estaduais e municipal.

Cursos chamados "Moda" e suas variações são $17 \%$ dos cursos na região Sudeste, $15 \%$ na região Sul, 1 na região Norte e 1 na região Nordeste. Devido à pouquíssima quantidade de cursos nestas regiões, elas seriam as que apresentam, proporcionalmente, a maior presença de cursos com o nome "Moda".

Quanto à oferta de cursos por instituições públicas, ela é maior na região Sul (10 cursos) do que na região Sudeste (9 cursos), mas nesta última a proporção de cursos de bacharelado nestas instituições é um pouco maior, e tais instituições não têm a vocação de ensino profissional dos Institutos Federais e Universidades Tecnológicas, que predominam na região Sul.

Tais distribuições, quando observadas à luz de outros fatores, como população, participação da indústria da moda no PIB, parque industrial, comércio, investimentos do poder público, podem ser úteis para verificar a vocação de cada região e o posicionamento de suas instituições quanto à atuação do docente e do discente na área de moda 6 .

\footnotetext{
${ }^{6}$ De fato, conforme observam alguns pesquisadores, é comum que os cursos tecnológicos sejam ofertados em regiões de grande presença de confecções e indústrias têxteis e em turnos noturnos. Revista ENSINARMODE, Florianópolis, Vol. 2, N. 1, Fevereiro-Maio 2018, p. 093-115. DOI: http://dx.doi.org/10.5965/25944630212018093 | ISSN 2594-4630
} 


\section{RE ARTE \\ MODA \\ DESIGN}

| http://www.revistas.udesc.br/index.php/Ensinarmode

As regiões Sul e Sudeste lideram a oferta de cursos e, dentre estes, os de bacharelados e em instituições públicas. Por outro lado, as regiões Centro-Oeste, Nordeste e Norte, ainda que com menos cursos, apresentam oferta de bacharelado e cursos com o nome de Moda em universidades federais, sinalizando uma preocupação com as marcas da valoração positiva nas categorias nome, grau acadêmico e categoria administrativa.

Quanto aos cursos tecnológicos, vimos que são maioria tanto em instituições privadas quanto públicas; também são majoritariamente chamados de Design de Moda; nas instituições públicas, são ofertados por aquelas voltadas à educação profissional, e isso se percebe mais claramente na região Sul. Como vimos, esta predominância do grau tecnológico na área da moda destoa da média nacional.

Algumas possíveis causas para esta discrepância já foram aventadas nas menções aos trabalhos de Queiroz (2014) e Aguiar (2015): a obrigatoriedade do enquadramento ao design e, dentro deste contexto, a maior facilidade de se obter bons resultados nas avaliações governamentais a partir da oferta no grau tecnológico, cujas diretrizes são mais claras e assertivas. Considerando que este trabalho se baseia na observação de dados secundários, o que tais dados podem nos dizer sobre a evolução da formação em moda no Brasil até a constituição deste cenário de predominância de cursos tecnológicos chamados Design de Moda?

\section{EVOLUÇÃO DA OFERTA DE CURSOS DE MODA NO BRASIL}

Se o levantamento apresentado na seção anterior tomava por base os dados do sistema e-MEC, para os objetivos desta seção consultamos os dados do Censo da Educação Superior, realizado anualmente pelo Inep - Instituto Nacional de Estudos e Pesquisas Educacionais.

Os dados oriundos deste censo estão disponíveis na página do Instituto na internet em diversas configurações: como microdados brutos, que podem ser cruzados de acordo com os interesses do pesquisador; em sinopses estatísticas, que apresentam estes dados já organizados em planilhas temáticas; e os resumos

Desta forma, eles atendem trabalhadores dessas empresas que buscam melhor seu futuro profissional com um curso superior. 


\section{RE ARTE \\ MODA \\ DESIGN}

técnicos, que relatam os principais resultados do Censo levando em conta os pedidos de informação mais frequentes (INSTITUTO..., 2015a).

O levantamento foi feito com base nas sinopses estatísticas, que são produzidas desde 1995 (INSTITUTO..., 2015b). A partir do ano 2000, o Inep passou a adotar a tabela da Classificação Internacional Eurostat/Unesco/OCDE para os cursos superiores. Diante disso, optamos por iniciar o levantamento a partir da sinopse deste ano.

As sinopses estatísticas do Inep trazem planilhas com diversos tipos de cruzamentos de informações sobre IES, cursos, docentes, discentes e muitas outras variáveis. Tais planilhas não mostram, no entanto, a distribuição de cursos por grau acadêmico (este cruzamento pode ser feito com análise dos microdados por meio de softwares específicos). O levantamento consistiu então na consulta das sinopses de 2000 a 2015 e na contagem dos cursos relacionados à moda que apareciam nestas sinopses, dando origem à tabela 1 .

O curso de Modelagem aparece uma única vez no Censo, em 2009. O curso de Estilismo é ofertado todos anos até 2009 (no levantamento de 2016 aparecem os bacharelados Design de Moda - Modelagem e Design de Moda - Estilismo). O curso de Gestão do Vestuário ocorre de 2003 a 2006, depois novamente apenas em 2015. Quanto aos cursos alocados em Engenharia, Produção e Construção/Têxteis, Roupas, Calçados e Couro, há uma ocorrência difusa de vários deles até fins da primeira década do ano 2000, com um pico de oferta em $2009-23$ cursos. A partir de 2010 os cursos desta área se estabilizam em três ofertas: Engenharia Têxtil, Indústria do Vestuário e Indústria Têxtil. Não apareceram cursos na modalidade EAD neste período. 


\section{RE ARTE \\ MODA \\ DESIGN}

Tabela 1 - Oferta de cursos relacionados à moda no Brasil (2000 a 2015).

\begin{tabular}{|c|c|c|c|c|c|c|c|c|c|c|c|c|c|c|c|c|}
\hline \multirow{2}{*}{ Subárea e curso } & \multirow[b]{2}{*}{00} & \multirow[b]{2}{*}{01} & \multirow[b]{2}{*}{02} & \multirow[b]{2}{*}{03} & \multirow[b]{2}{*}{04} & \multirow[b]{2}{*}{05} & \multirow[b]{2}{*}{06} & \multicolumn{2}{|c|}{ Ano $20 \ldots$} & \multirow[b]{2}{*}{09} & \multirow[b]{2}{*}{10} & \multirow[b]{2}{*}{11} & \multirow[b]{2}{*}{12} & \multirow[b]{2}{*}{13} & \multirow[b]{2}{*}{14} & \multirow[b]{2}{*}{15} \\
\hline & & & & & & & & 07 & 08 & & & & & & & \\
\hline Design e Estilismo & 19 & 20 & 24 & 35 & 52 & 61 & 76 & 84 & 101 & 128 & 127 & 126 & 132 & 135 & 137 & 148 \\
\hline Desenho de Moda & 3 & 4 & 4 & 7 & 13 & 21 & 27 & 61 & 78 & 77 & 122 & 76 & 80 & 83 & 85 & 95 \\
\hline Estilismo & 2 & 1 & 1 & 1 & 1 & 3 & 4 & 1 & 1 & 3 & & & & & & \\
\hline Moda & 14 & 15 & 19 & 27 & 38 & 37 & 45 & 22 & 22 & 47 & 5 & 50 & 52 & 52 & 52 & 53 \\
\hline Modelagem & & & & & & & & & & 1 & & & & & & \\
\hline $\begin{array}{l}\text { Gerenciamento e } \\
\text { Administração }\end{array}$ & 0 & 0 & 0 & 1 & 1 & 2 & 3 & 0 & 0 & 0 & 0 & 0 & 0 & 0 & 0 & 1 \\
\hline $\begin{array}{l}\text { Gestão da produção de } \\
\text { vestuário }\end{array}$ & & & & 1 & 1 & 2 & 3 & & & & & & & & & 1 \\
\hline $\begin{array}{l}\text { Têxteis, Roupas, } \\
\text { Calçados e Couro }\end{array}$ & 5 & 6 & 9 & 9 & 12 & 15 & 16 & 19 & 19 & 23 & 21 & 20 & 18 & 16 & 15 & 16 \\
\hline Confecção de roupas & 1 & 1 & 1 & 1 & 1 & 1 & & & & 1 & & & & & & \\
\hline $\begin{array}{l}\text { Engenharia de produção } \\
\text { têxtil }\end{array}$ & 1 & 1 & 1 & 1 & 1 & 1 & 1 & & & & & & & & & \\
\hline Engenharia industrial têxtil & & & & & & 1 & 1 & 1 & 1 & 2 & & & & & & \\
\hline Engenharia têxtil & 2 & 3 & 3 & 3 & 3 & 2 & 2 & 2 & 2 & 3 & 5 & 5 & 4 & 4 & 5 & 5 \\
\hline Indústria do vestuário & & & 2 & 3 & 5 & 6 & 7 & 11 & 11 & 10 & 10 & 10 & 9 & 8 & 6 & 6 \\
\hline Indústria têxtil & 1 & 1 & 2 & 1 & 2 & 3 & 4 & 4 & 4 & 4 & 6 & 5 & 5 & 4 & 4 & 5 \\
\hline Têxtil, vestuário e calçados & & & & & & 1 & 1 & 1 & 1 & 3 & & & & & & \\
\hline
\end{tabular}

Fonte: Elaborada pela autora com base em dados de INSTITUTO... (2015b).

Quanto aos cursos da subárea Estilismo e Design, observe-se também a expressão visual de sua distribuição no decorrer deste período de 16 anos (Gráfico 1). Considerando os dois mais representativos, Moda e Desenho de Moda (entendido aqui como um outro nome para Design de Moda), como um conjunto, percebe-se que, até 2003, Desenho de Moda tinha participação menor neste conjunto, entre 17\% e 20\%. Em 2004 essa participação sobe para 25\% e, em 2005, alcança $36 \%$. Este aumento coincide com o período em que as Diretrizes Curriculares Nacionais do curso de Graduação em Design são aprovadas pelo Ministério da Educação (CONSELHO..., 2004). A partir daí, "[...] os bacharelados em Moda, que até então possuíam uma infinidade de nomenclaturas distintas, passaram a pertencer à área do Design, enquanto os tecnológicos utilizaram o termo Design de Moda" (QUEIROZ, 2014, p. 95).

A regulamentação dos tecnológicos parece ser mais um fator relacionado ao grande salto na oferta de cursos de Design de Moda que acontece de 2006 para 2007. É neste período que a proporção se inverte e estes aparecem em maior 


\section{RE ARTE \\ MODA \\ DESIGN}

quantidade que os de Moda. Mas não há apenas a "substituição" de um curso por outro, e sim um aumento efetivo no total de cursos ${ }^{7}$.

Gráfico 1 - Oferta de cursos relacionados à moda no Brasil (2000 a 2015)

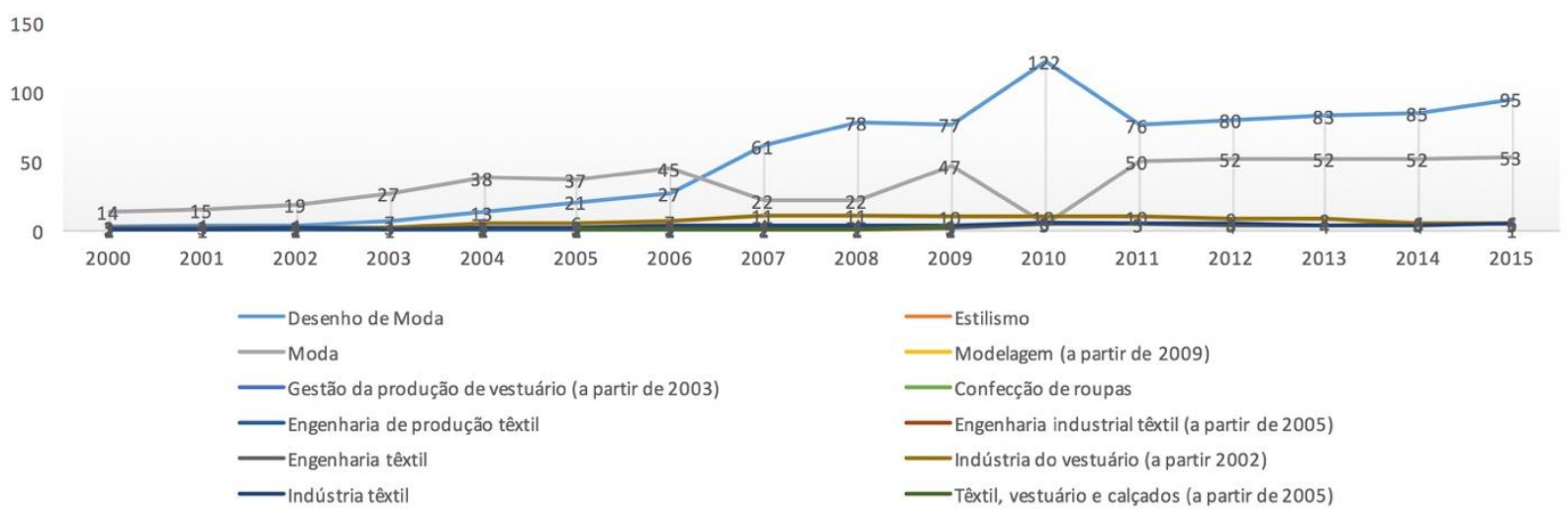

Fonte: Elaborado pela autora com base em dados de INSTITUTO... (2015b).

A predominância do Design de Moda atinge seu ápice em 2010 e, depois disso, a relação volta aos patamares dos anos pós-Resolução, com o curso de Moda representando entre $35 \%$ e 39\% do conjunto. No Censo de 2015 (o mais recente na época da consulta), os cursos de Moda são pouco mais de $35 \%$ do conjunto. No levantamento de 2016, feito pelo e-MEC, os cursos de Moda são aproximadamente $10 \%$ do total.

Como já justificado anteriormente, esta análise não identifica o grau acadêmico dos cursos. No entanto, se a oferta majoritária de cursos tecnológicos de Design de Moda constatada em 2016 tiver sido uma tendência a partir da regulamentação da graduação tecnológica em 2006 - de fato, Queiroz também observa essa predominância, nos anos de 2011 e 2014, tomando por base o e-MEC (2004, p. 97) -, pode-se supor que boa parte dos cursos de Design de Moda contabilizados na tabela 1, no decorrer dos anos, seja deste grau.

\footnotetext{
${ }^{7}$ Não se sabe, também, se a partir de 2004 os bacharelados em Design de Moda passaram a ser cadastrados nos sistemas do Inep como cursos de Design que teriam ênfase em Moda, ou se efetivamente foram cadastrados com o termo Moda junto a Design, resultando nas quantidades apresentadas por este levantamento. Queiroz observa que "Os cursos de bacharelado devem se chamar Design, e os cursos tecnológicos Design de Moda. Por questões diversas, cujas razões desconhecemos, há bacharelados denominados Design de Moda" (2004, p. 81, nota 18).
} 


\section{RE ARTE \\ MODA \\ DESIGN}

| http://www.revistas.udesc.br/index.php/Ensinarmode

Esta inversão da predominância de Moda para Design de Moda - que no levantamento deste artigo é identificada a partir de 2007 e que Queiroz localiza em 2011 (2014, p. 98) -, pode ser compreendida por diversos fatores, dentre eles:

[...] como uma resposta a um suposto aumento da demanda do mercado por este profissional mais tecnicista, mas, em alguns casos, como uma fuga aos exames do ENADE que, desde 2006, trazem questões predominantemente do campo do Design. [...] Os cursos tecnológicos, por outro lado, são submetidos a provas com questões específicas de produtos têxteis e de vestuário (QUEIROZ, 2014, p. 98).

As mudanças na legislação e na forma de avaliação dos cursos discutidas até agora parecem explicar a maior parte dos movimentos observados no gráfico 1 , exceto pela grande disparidade de 2010, que não se mantém nos anos seguintes. Uma hipótese é que se trate de uma distorção provocada por critérios de cadastramento.

\section{OS CURSOS DE MODA TECNOLÓGICOS}

Visto que o curso denominado apenas "Moda" ainda resiste no bacharelado ao menos nos levantamentos aqui apresentados - mesmo mais de uma década após a resolução que o "enquadra" no Design, supõe-se que o embate entre o enquadramento e a independência continua ativo. A oferta de cursos de moda em grau tecnológico, regulamentada de forma precisa desde o início, tem a característica de não levantar as discussões que se realizam em relação ao bacharelado. As orientações são bem delimitadas e claras. Se isso deixa pouca margem para adaptações, por outro lado facilita a implantação. Parece ser uma proposta mais estável e assertiva, como mostram os catálogos de cursos tecnológicos publicados até agora.

Em 2006, o Decreto № 5.773, que "dispõe sobre o exercício das funções de regulação, supervisão e avaliação de instituições de educação superior e cursos superiores de graduação e sequenciais no sistema federal de ensino", determinava que "o reconhecimento e a renovação de reconhecimento de cursos superiores de tecnologia terão por base catálogo de denominações de cursos publicado pela Secretaria de Educação Profissional e Tecnológica" (BRASIL, 2006, grifo nosso). 


\section{RE ARTE \\ MODA \\ DESIGN}

| http://www.revistas.udesc.br/index.php/Ensinarmode

O primeiro catálogo saiu em $2006^{8}$, com a função de organizar e orientar "[...] a oferta de Cursos Superiores de Tecnologia, inspirado nas Diretrizes Curriculares Nacionais para a Educação Profissional de Nível Tecnológico e em sintonia com a dinâmica do setor produtivo e os requerimentos da sociedade atual" (HADDAD, 2006, p. 7). A ideia é que todos os cursos tecnológicos sigam as orientações deste documento, ainda que sejam permitidas algumas adaptações regionais.

Este primeiro catálogo apresenta 98 graduações distribuídas em 10 eixos (MINISTÉRIO DA EDUCAÇÃO, 2006). São três os cursos relacionados à indústria da moda: Produção de Vestuário e Produção Têxtil, incluídos no eixo Produção Industrial e com carga mínima de 2.400 horas; e Design de Moda, incluído no eixo Produção Cultural e Design e com carga mínima de 1.600 horas.

Posteriormente foram publicadas duas outras edições, em 2010 (MINISTÉRIO DA EDUCAÇÃO, 2010) e em 2016 (MINISTÉRIO DA EDUCAÇÃO, 2016), com atualização da quantidade de eixos e cursos e revisão dos descritores. Em 2010, os eixos sobem para 13 e os cursos para 113; em 2016 permanecem os 13 eixos e os cursos aumentam para 134. Não há inclusão de outros cursos do setor da moda, além dos já mencionados, e nem há alteração dos eixos em que estes cursos estão alocados. Há sim uma atualização nos descritores do curso de Design de Moda no decorrer das edições. Antes de tratar delas, vale observar a descrição do eixo em que o curso se enquadra, na edição de 2016 :

\footnotetext{
O eixo tecnológico de PRODUÇÃO CULTURAL E DESIGN compreende tecnologias relacionadas com representações, linguagens, códigos e projetos de produtos, mobilizadas de forma articulada às diferentes propostas comunicativas aplicadas. Abrange criação, desenvolvimento, produção, edição, difusão, conservação e gerenciamento de bens culturais $e$ materiais, ideias e entretenimento aplicadas em multimeios, objetos artísticos, rádio, televisão, cinema, teatro, ateliês, editoras, vídeo, fotografia, publicidade e projetos de produtos industriais (MINISTÉRIO..., 2016, p. 98, grifo nosso).
}

Gostaríamos de destacar aqui a visão da moda, junto a outros produtos, como um bem cultural e material (note-se o uso do "e", não do "ou"), ou seja, um produto híbrido (CIETTA, 2017), cujas dimensões cultural e manufatureira possuem a

\footnotetext{
${ }^{8}$ Recorde-se o aumento dos cursos de Design de Moda entre 2006 e 2007 (tabela 1). Os dados não informam se o curso é bacharelado ou tecnológico, mas a regulamentação destes últimos em 2006 sugere que parte deste aumento seja fruto da oferta de tecnológicos.
} 


\section{RE ARTE MODA DESIGN}

| http://www.revistas.udesc.br/index.php/Ensinarmode

mesma importância. Enquanto a subárea de Design e Estilismo da classificação OCDE - que parametriza os cursos no Inep em qualquer grau acadêmico - fala em "criação e concepção" (EUROSTAT; UNESCO; OCDE, 2000), a descrição do eixo em que está o Design da Moda, específica dos cursos tecnológicos, aborda, além da criação, a questão da produção e do gerenciamento. No entender de Enrico Cietta, estas são competências indispensáveis: não se pode esquecer que

[...] a criatividade distribuída já é uma realidade na indústria da moda e que ela opera transversalmente às funções e consequentemente à organização empresarial. Temos necessidade então de dar maior atenção às funções empresariais que por anos foram negligenciadas (CIETTA, 2017, p. 48).

Voltando aos descritores do curso de Design de Moda, observe-se os textos das edições de 2006, 2010 e 2016 do catálogo (quadro 1):

Quadro 1 - Descritores do perfil profissional do concluinte do curso de Design de Moda no Catálogo Nacional de Cursos Superiores de Tecnologia (2006, 2010, 2016)

\begin{tabular}{|c|c|c|}
\hline Catálogo de 2006 & Catálogo de 2010 & Catálogo de 2016 \\
\hline $\begin{array}{l}\text { "O Tecnólogo em Design de } \\
\text { Moda elabora e gerencia } \\
\text { projetos para a indústria de } \\
\text { confecção do vestuário, } \\
\text { considerando fatores estéticos, } \\
\text { simbólicos, ergonômicos e } \\
\text { produtivos. A pesquisa de } \\
\text { tendências de comportamento, } \\
\text { cores, formas, texturas e } \\
\text { acabamentos; o estilismo em } \\
\text { moda; o desenvolvimento de } \\
\text { produtos de moda aplicando } \\
\text { visão histórica, sociológica e } \\
\text { prospectiva; a elaboração de } \\
\text { portifólios e dossiês; a } \\
\text { representação gráfica de suas } \\
\text { criações; a elaboração de } \\
\text { protótipos e modelos, além da } \\
\text { análise de viabilidade técnica do } \\
\text { projeto, são algumas das } \\
\text { atividades deste profissional" } \\
\text { (MINISTÉRIO, 2006, p. 41). }\end{array}$ & $\begin{array}{l}\text { "O tecnólogo em Design de } \\
\text { Moda elabora e gerencia } \\
\text { projetos para a indústria de } \\
\text { confecção do vestuário, } \\
\text { considerando fatores estéticos, } \\
\text { simbólicos, ergonômicos e } \\
\text { produtivos. A pesquisa de } \\
\text { tendências de comportamento, } \\
\text { cores, formas, texturas e } \\
\text { acabamentos; o estilismo em } \\
\text { moda; o desenvolvimento de } \\
\text { produtos de moda aplicando } \\
\text { visão histórica, sociológica e } \\
\text { prospectiva; a elaboração de } \\
\text { portfólios e dossiês; a } \\
\text { representação gráfica de suas } \\
\text { criações; a elaboração de } \\
\text { protótipos e modelos, além da } \\
\text { análise de viabilidade técnica do } \\
\text { projeto, são algumas das } \\
\text { atividades deste profissional" } \\
\text { (MINISTÉRIO, 2010, p. 86). }\end{array}$ & $\begin{array}{l}\text { "Cria e desenvolve produtos } \\
\text { para a indústria da moda. } \\
\text { Analisa e aplica fatores } \\
\text { estéticos, simbólicos, } \\
\text { ergonômicos, socioculturais e } \\
\text { produtivos. Realiza pesquisa de } \\
\text { moda. Planeja, gerencia e } \\
\text { articula coleções de moda com } \\
\text { processos de fabricação, } \\
\text { matérias-primas e viabilidade } \\
\text { técnica e sustentável. Elabora } \\
\text { protótipos, modelos, croquis, } \\
\text { fichas técnicas e portfólios com } \\
\text { uso de técnicas diferenciadas de } \\
\text { expressão gráfica. Avalia e } \\
\text { emite parecer técnico em sua } \\
\text { área de formação" (2016, p. } \\
\text { 103). }\end{array}$ \\
\hline
\end{tabular}

Fonte: Adaptado de MINISTÉRIO, 2006; MINISTÉRIO, 2010; MINISTÉRIO, 2016.

Os descritores são os mesmos em 2006 e 2010, mas mudam em 2016. A expressão "indústria de confecção do vestuário" é substituída por "indústria da 


\section{RE ARTE \\ MODA \\ DESIGN \\ | http://www.revistas.udesc.br/index.php/Ensinarmode}

moda"; a pesquisa de tendências, de comportamento e de materiais vira "pesquisa de moda"; aparecem de forma mais explícita as competências de planejamento e gerenciamento de produção, que são apenas sugeridas nos descritores anteriores.

Se as especificidades dos primeiros itens são substituídas pela expressão mais geral de moda, talvez haja uma intenção de mostrar uma ampliação da área de atuação deste profissional ou de deixar espaço para a flexibilização da oferta por parte das IES. Por outro lado, a especificidade das competências de produção, incluindo a preocupação com a sustentabilidade, mostra uma visão de que a criação não pode estar dissociada da compreensão da cadeia produtiva como um todo.

Os ajustes são poucos e ocorrem após dez anos de "estabilidade" dos descritores anteriores. $O$ que isso pode significar, considerando também o aumento dos cursos de moda no Brasil? Será que a formação em moda predominantemente no grau tecnológico e embasada pelo aporte teórico e temático do design converteuse, por fim, em uma estratégia bem-sucedida?

\section{CONSIDERAÇÕES FINAIS}

A motivação para a realização da pesquisa apresentada neste artigo surgiu, como dissemos, da observação de uma relação intrigante entre o nome de cursos de moda e o grau acadêmico de sua oferta. A maioria dos cursos é chamada de Design de Moda e é ofertada em grau tecnológico. Até aí, nenhuma novidade: os estudos citados apresentam as causas - as determinações do Ministério da Educação, em primeiro lugar, com efeito específico nesta área, e o incentivo governamental à educação tecnológica, que afeta de forma mais geral o ensino superior brasileiro -, que são situações já familiares para quem atua na educação em moda. O que chama a atenção é a presença, ainda, de cursos chamados Moda, ofertados principalmente em grau bacharelado. Infere-se daí uma relação que homologa elementos axiologizados euforicamente em suas respectivas categorias, e outra que homologa os elementos disfóricos.

O trabalho quis investigar como se dá essa relação ao ser observada nos estados e regiões do Brasil, e nos tipos de instituição em que os cursos são ofertados. O que emerge de mais interessante é a presença dos bacharelados em 


\section{RE ARTE \\ MODA \\ DESIGN}

Moda especialmente em Universidades Federais e Estaduais, instituições vocacionadas, ao menos discursivamente, para a formação científica. Cursos tecnológicos chamados Design de Moda, quando ofertados por instituições públicas, o são principalmente pelos institutos federais ou universidades tecnológicas. As instituições privadas não fazem a mesma distinção: tanto faculdades quanto centros universitários e universidades ofertam cursos neste grau e com este nome.

Quanto às regiões, Sul e Sudeste abrigam a maior parte dos cursos. Se formos considerar a população de cada região, o Sul teria uma relação maior de cursos por habitante. A distribuição de cursos de bacharelado e de Moda é equilibrada entre as duas, bem como a oferta em instituições públicas. O Sul destaca-se, no entanto, por ofertar cursos gratuitos especialmente de Design de Moda em grau tecnológico. As regiões Norte, Nordeste e Centro-Oeste, ainda que com menos cursos, mantêm uma tendência de oferta do curso de Moda como bacharelado em instituição pública, especialmente federal.

Um segundo objetivo da pesquisa era verificar as possíveis explicações para a discrepância da relação entre tecnológicos e bacharelados na moda e na média nacional. Na moda, como vimos, os tecnológicos são maioria, ao contrário do que se observa no contexto geral. Neste trabalho, buscamos algumas destas explicações nos números e nos textos verbais disponibilizados pelo Ministério da Educação.

É possível perceber que o enquadramento ao design e a regulamentação dos cursos tecnológicos tiveram um forte impacto na formação em moda. A mudança na legislação não apenas alterou o nome: ela incentivou a abertura de novos cursos, em grau tecnológico. Por outro lado, a manutenção de cursos chamados Moda e em grau bacharelado em meio a esse contexto parece ter delineado mais claramente ao menos no discurso - uma distinção entre as vocações e as valorações de cada curso: bacharelado em Moda para o criar/pensar, tecnológico em Design de Moda para o fazer.

Mas, se existe uma axiologia que valoriza positivamente a Moda e o bacharelado, o que explicaria o sucesso dos cursos de Design de Moda tecnológicos, e sua oferta por instituições públicas, ainda que voltadas ao ensino técnico profissional? Seguindo a linha proposta neste trabalho, que busca respostas 


\section{RE ARTE \\ MODA \\ DESIGN}

em dados secundários, algumas pistas podem estar justamente nos Catálogos de Cursos.

$\mathrm{Na}$ qualidade de publicações do Governo Federal eles já manifestam uma atenção, uma preocupação com esse tipo de formação, que se alinha às avaliações mais assertivas e, portanto, que beneficiam os alunos desses cursos (e suas instituições). Torna-se mais fácil implantar e manter esses cursos, bem como posicioná-los no mercado, tanto para os alunos quanto para as empresas que empregarão os egressos. E ao observar o conteúdo destes Catálogos, nota-se nos descritores dos cursos relacionados à moda um não privilégio do caráter artístico e quase genial da criação, simultaneamente ao aumento da importância dos aspectos de fundamentação teórica e técnica.

Esta mudança de posicionamento sobre a atuação em moda pode estar atraindo mais interessados. Ou seja, o aumento do interesse não teria a ver apenas com cursos mais rápidos, mais "baratos"(?) e mais curtos, mas também com uma "democratização" do campo de conhecimento e do acesso a este setor cuja importância na economia brasileira só tem aumentado. É certo que a moda em si está na moda, mas trabalhar com isso, seguir uma carreira no comércio, na indústria ou na pesquisa desta área torna-se mais factível quando se abrem outras possibilidades além daquelas da criação.

Por fim, as dicotomias trazidas a todo momento neste trabalho não refletem o pensamento da autora e muito menos sugerem que se trata de uma realidade intrínseca da formação em moda; no entanto, parecem estar ainda presentes em certos discursos sobre o tema e, como o trabalho quis mostrar, nos dados numéricos disponibilizados pelo Ministério da Educação. Estes dados, se estão longe de dizerem tudo, ao menos nos dizem muito, na medida em que também constituem discursos sobre o assunto investigado.

\section{REFERÊNCIAS}

AGUIAR, Grazyella Cristina Oliveira de. Cursos superiores de moda no Brasil: regulamentações, evoluções, perspectivas. In: COLÓQUIO DE MODA, 11., 2015, Curitiba. Anais... Curitiba: Abepem/Universidade Positivo, 2015. Disponível em: < http://www.coloquiomoda.com.br/anais_ant/anais/11-Coloquio-de- 


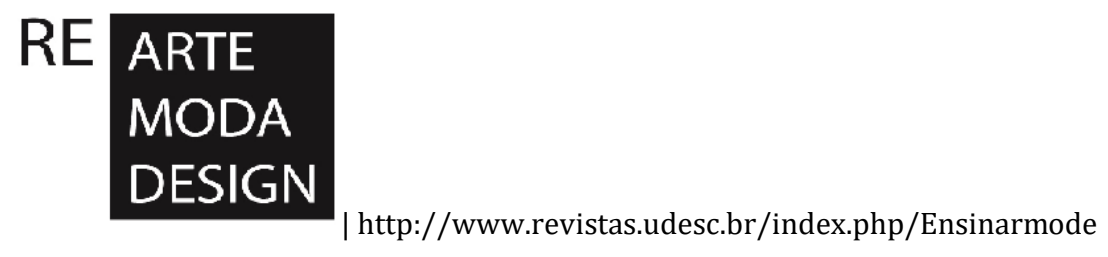

Moda_2015/ARTIGOS-DE-GT/GT01-EDUCACAO-TEORIA-E-PRATICA-EMMODĀGT-1-CURSOS-SUPERIORES-DE-MODA-NO-BRASIL.pdf>. Acesso em: 27 dez. 2017.

BRASIL. Decreto n 5.773, de 9 de maio de 2006. Ministério da Educação, Brasília, 10 maio 2006.2 Disponível em: $<$ http://portal.mec.gov.br/setec/arquivos/pdf_legislacao/rede/legisla_rede_dec5773.pdf>. Acesso em: 10 jul. 2017.

CIETTA, Enrico. A economia da moda: porque hoje um bom modelo de negócios vale mais do que uma boa coleção. Tradução de Adriana Tulio Baggio. São Paulo: Estação das Letras e Cores, 2017.

CONSELHO NACIONAL DE EDUCAÇÃO. Resolução n 5, de 8 de março de 2004. Aprova as Diretrizes Curriculares Nacionais do Curso de Graduação em Design e dá outras providências. Ministério da Educação, Brasília, 8 mar. 2004. Disponível em: <http://portal.mec.gov.br/cne/arquivos/pdf/rces05_04.pdf>. Acesso em: 10 jul. 2017.

E-MEC. Instituições de Educação Superior e Cursos Cadastrados. Brasília, 2017. Disponível em: <http://emec.mec.gov.br>. Acesso em: 10 dez. 2016.

EUROSTAT; UNESCO; OCDE. Classificação Internacional: Área de Formação e Treinamento. Manual de Classificação. Tradução e adaptação: INSTITUTO NACIONAL DE ESTUDOS E PESQUISAS EDUCACIONAIS. Brasília: O Instituto, 2000. (Texto original publicado em 1999).

GREIMAS, Algirdas Julien; COURTÉS, Jospeh. Dicionário de Semiótica. Tradução de Alceu Dias Lima et. al. São Paulo: Contexto, 2008.

HADDAD, Fernando. Apresentação. In: MINISTÉRIO DA EDUCAÇÃO. Catálogo Nacional de Cursos Superiores de Tecnologia. 1. ed. Brasília: O Ministério, 2006.

INSTITUTO NACIONAL DE ESTUDOS E PESQUISAS EDUCACIONAIS. Censo da Educação Superior. Brasília, 20 out. 2015a. Disponível em: <http://portal.inep.gov.br/web/guest/censo-da-educacao-superior>. Acesso em: 10 jul. 2017.

Sinopses Estatísticas da Educação Superior - Graduação. Brasília, 20 out. 2015b. Disponível em: <http://portal.inep.gov.br/web/guest/sinopses-estatisticas-daeducacao-superior>. Acesso em: 10 jul. 2017.

Resumo técnico: Censo da educação superior 2014. Brasília: O Instituto, 2016.

MINISTÉRIO DA EDUCAÇÃO. Catálogo Nacional de Cursos Superiores de Tecnologia. 1. ed. Brasília: O Ministério, 2006.

Catálogo Nacional de Cursos Superiores de Tecnologia. 2. ed. Brasília: $O$ Ministério, 2010. 


\section{RE ARTE \\ MODA \\ DESIGN \\ | http://www.revistas.udesc.br/index.php/Ensinarmode}

Catálogo Nacional de Cursos Superiores de Tecnologia. 3. ed. Brasília: O Ministério, 2016.

QUEIROZ, Cyntia Tavares Marques de. Do estilismo ao design: Os currículos do bacharelado em moda da Universidade Federal do Ceará. 2014. 197f. Tese (Doutorado) - Universidade Federal do Ceará, Programa de Pós-graduação em Educação Brasileira, Fortaleza, 2014.

Recebido em: 27/12/2017

Aceito em: 01/02/2018 